\title{
The Effect of 8 Weeks Rhythmic Aerobic Exercise on Vaspin Levels and Lipid Profile in Overweight and Obese Women
}

\author{
Ahmad Shahdadi \\ ${ }^{1}$ Assistant Professor, Faculty of Physical Education and sport, Department of Physical Education \\ University of Sistan and Baluchestan, Zahedan, Iran
}

\begin{abstract}
Khadijeh Molaei
2MSc student in Exercise Physiology, Faculty of Physical Education and sport, Department of Physical Education University of Sistan and Baluchestan, Zahedan, Iran; Email of Corresponding Author: kh.molaei@pgs.usb.ac.ir
\end{abstract}

Doi:10.5901/mjss.2016.v7n4s2p163

\section{Abstract}

Obesity as a chronic disease causes many diseases. Vaspin is a new adipokine, which increase as a result of inflammation resulting from obesity and metabolic diseases (3). Regular exercise has a variety of benefits, including increasing insulin sensitivity, controlling blood sugar (glucose), losing weight, decreasing body fat percentage, reducing inflammation stress. Kadoglou et al. (2013) reported that six months aerobic exercise with 65 to 75 per cent of maximum heart rate causes increasing serum vaspin level in type II diabetes patients. While Eberbach et al. (2010) reported decreasing serum vaspin after intense training. Different factors and mechanisms involve in the development of cardiovascular diseases, the most important factors are changes in inflammatory factors and lipids disorder including poor concentration of HDL, LDL, TG, and TC (4). The aim of this study is to investigate the effects of 8 weeks rhythmic aerobic exercise on vaspin and lipid profile in overweight and obese women. After calling among women, 34 people of overweight and obese women (40 \pm 10 years, BMI $\geq 25)$ in Zahedan on a voluntary basis and available and based on inclusion and exclusion criteria were selected. Then, the subjects were randomly divided into two groups of training $(n=17)$ and control $(n=17)$. The training group commenced training in an 8-week training program, three sessions per week (each session 60 minutes), with 55 per cent of maximum heart rate during the first week, and gradually, with the development of training programs reached 85 per cent of maximum heart rate. Each workout included the aerobic movements of low impact and high impact in a standing posture and returning to the primary state in a sitting posture. While, were asked the control group to maintain their normal lifestyle during the study. Blood samples in two stages were taken: first, 48 hours before the test and then, 48 hours after the last meeting of rhythmic aerobic exercise. Serum vaspin concentration and lipid profiles were determined by ELISA method using a special kit. To recognize similarity and normality of the data related to the subjects of the research groups was used Shapiro-Wilk test. To analyze the data was used the paired $T$ test and the covariance test to show differences within group and between groups at the level of $5 \%$. Statistical calculations were done by SPSS 21. Data analysis showed that 8-week exercise had a significant effect on $B M I(P=0.001)$, weight $(P=0.000)$, vaspin $(P=0.003), H D L(P=0.000), L D L(P=0.001)$, and TC $(P=0.001)$, while had no significant effect on TG $(P=0.692)$. Exercise intervention with respect to the basis levels of vaspin may show different effects. In other words, the health of the subjects, overweight and lack of physical activity can be one of influences in response to this variable to physical activity. Hence, it seems that in this study, a significant decrease in BMI of the experimental group than in the control group and most likely, reducing inflammatory levels has led to the adjusted response in vaspin levels. Furthermore, aerobic exercise can be considered as the effective method for changing in the lipid profile. It seems that physical activities also cause increasing lipolysis and reducing fatty acids in the blood and muscles.

\section{Introduction}

Obesity as a chronic disease causes many diseases such as hypertension, mellitus diabetes, hyperlipidemia, coronary heart diseases and some cancers (breast, uterus, prostate, and colon) $(22,7)$, and an independent factor for increasing mortality is counted $(36,7)$. Lack of physical activity and inactive lifestyle is an effective factor in the prevalence of overweight and obesity (15). Such conditions lead to the disruption of the interaction between metabolic and immune processes (3). Adipose tissue is a very complex and active endocrine and metabolic organ, which is not only responsible for the transmission of afferent signals from different hormone systems and the central nervous system, but also recent research findings indicate that adipose tissue as a multipurpose endocrine undertakes the production and secretion of various types of bioactive peptides, which are under various adipokines (34). adipokines involved in the regulation of systemic processes such as food consumption, food metabolism, insulin sensitivity, stress response, reproduction, bone 
growth and inflammation (10). Several adipokines is secreted by adipose tissue, including the chemerin, apelin, omentin, and vaspin (10).

Vaspin is a new adipokine belonging to serpentine family, which was discovered to examine the relationship between obesity and insulin resistance in different experimental procedures on rats that were a genetic model of type II diabetes. The mice are characterized with visceral obesity, insulin resistance, hyperinsulinemia, hypertension and dyslipidemia (17). Vaspin was isolated from visceral adipose tissue in 2000. This adipokine is a protein that its molecular weight is equal to $47 \mathrm{kDa}$ (16). Vaspin protein in rats, mice, and humans are formed of 412, 414, and 415 amino acid, respectively. This gene has codes with molecular weight $8.1 \mathrm{~kb}$, on which chromosome 14 is drawn and its levels is related to losing weight and reducing several factors, including obesity and metabolic disorders (16). In many patients affected by polycystic ovary syndrome and insulin resistance, obesity and glucose intolerance is associated with disruption in producing vaspin (10). Metabolic changes resulting from this hormone have an important effect on adipose tissue, muscle, liver, and inflammation and are related to metabolic syndrome diseases (10). Hence, it seems that one of the effective factors that affect Vaspin hormone is physical activity. It is an appropriate strategy for the prevention and treatment of obesity and many diseases related to it such as cardiovascular diseases. Physical activity decreases mortalities resulting from cardiovascular diseases and obesity.

Physical activities in different ways can be effective and on the subject of effective physical activities (intensity, duration, type and number of sessions per week) for reducing adipose tissue in healthy and sick people, there are different recommendations (11). Regular exercise has a variety of benefits, including increasing insulin sensitivity, controlling blood sugar (glucose), losing weight, decreasing body fat percentage, reducing hypertension, and decreasing suffering from cardiovascular diseases (6). There are few studies that have examined the effect of exercise on vaspin. Kadoglou et al. (2013) reported that six months aerobic exercise with 65 to 75 per cent of maximum heart rate causes increasing serum vaspin level in type II diabetes patients (14). In addition, Kloting et al. (2012) stated that insulin sensitivity is, in fact, the important and strong determinant of vaspin gene expression in adipose tissue, and high vaspin levels in the diabetics and obese people is, in fact, a compensatory mechanism in response to decreasing insulin sensitivity and reducing glucose metabolism (18). While Eberbach et al. (2010) reported decreasing serum vaspin after intense training. In their sight, this reduction is resulting from the oxidative activity stress (21). Furthermore, Chang et al. (2010) showed that a 12-week program of aerobic exercise on 20 to 65-year-old obese people causes reducing body composition and serum vaspin levels (8). Handisurya et al. (2010) in their study, which was conducted to examine vaspin concentration in relation to insulin sensitivity after weight loss resulting from laparoscopy, showed that weight loss after surgery in 33 subjects with excessive obesity leads to decrease vaspin levels, insulin, BMI, and insulin resistance. In addition, changing in the concentration of serum vaspin has a positive correlation with changing in insulin resistance and insulin (10). Hida et al. (2000) observed the highest serum vaspin levels in OLETF rats at the 30-week age. Increasing age and losing weight in these mice was associated with a significant reduction in serum vaspin levels. However, in mice that had optional exercise on a running wheel, similar to insulin treatment, serum vaspin levels were normal (12). While Safarzadeh et al. (2012) showed increasing serum vaspin concentration (2).

Different factors and mechanisms involved in the development of cardiovascular diseases, which the most of them include changes in factors in relation to inflammation and coagulation, including the inadequate levels of cytokines (particularly IL-1 and IL-6), reactive protein (C19), lipid disorders, such as low concentration of HDL, LDL, TG, TC and smoking (23). The concentration of HDL (high-density lipoprotein) is indirectly related to coronary heart disease and the concentration of LDL (low-density lipoprotein) is directly related to coronary heart disease. Hence, the LDL to HDL ratio is a good predictor of coronary heart disease risk (32). Aerobic exercise has beneficial effects in reducing the risk of cardiovascular disease has been shown in numerous studies $(19,7)$. Many studies have shown that aerobic exercise is associated with low levels of LDL-C and TC in the serum $(10,24)$. Given the importance of Vaspin hormone associated with various diseases and inconsistent results of studies mentioned-above, it seems that the present research is essential due to limited studies on the effect of aerobic and anaerobic activities on vaspin levels as well as since in our current society, there are different interests concerning the type of physical activity (some people are interested in different types of rhythmic aerobic exercises). Therefore, the aim of the present study is the effect of 8 weeks rhythmic aerobic exercise on vaspin levels and lipid profile in overweight and obese women. Regarding the limited internal investigations in relation to the changes of vaspin and physical activity, as well as the development of community interest in rhythmic physical activities, including aerobics, in this study was addressed to evaluate the changes in vaspin levels associated with the 8 weeks rhythmic aerobic exercise. 


\section{Materials and Methods}

\subsection{Data collection methods}

After calling among women, 34 people of overweight and obese women in Zahedan on a voluntary basis and available and based on inclusion and exclusion criteria were selected. The criteria were: 1) having overweight and obesity (BMI $\geq$ 25); 2) a minimum age of 30 years and a maximum age of 50 years.

Exclusion criteria of research included: 1) cardiovascular diseases, severe hypertension, type I and type II diabetes, diseases associated with thyroid; 2) the consumption of drug; 3) smoking and alcohol; 4) lack of participating in any regular physical activity during the last 6 months. At the time of the accomplishment of the research, the samples had no special diet. By reason of the experimental nature of the study and the observance of moral principles, at first, the consent form to participate in the research and medical history questionnaire was completed by subjects. Then, the subjects were randomly divided into two groups of training $(n=17)$ and control $(n=17)$. The training group participated in an 8-week training program, and three sessions per week, While, were asked the control group to maintain their normal lifestyle during the study.

\subsection{Training protocol}

Rhythmic aerobic exercise program consisted of 8 weeks rhythmic aerobic exercise, 3 sessions per week, and each session 60 minutes, with 55 per cent of maximum heart rate during the first week, and gradually, with the development of training programs reached 85 per cent of maximum heart rate. Each workout included a warm-up (stretching movements and jogging for 10 minutes), the main part of the training containing the aerobic movements of low impact and high impact in a standing posture (40 minutes) and returning to the primary state in a sitting posture (10 minutes). It is noted that the control group did not participate in any regular physical activity within a period of the accomplishment of the research. Maximum heart rate of participants in the training was calculated with the Polar heart rate monitor. The protocol was conducted at the indoor gymnasium with adequate ventilation and the gymnasium was similar in terms of temperature and holding hours throughout the whole time of 8 weeks.

\subsection{Measuring blood variables}

Blood samples in two stages were taken: first, 48 hours before the test and then, 48 hours after the last meeting of rhythmic aerobic exercise in order to eliminate the effect of the training, in the laboratory between the hours of 7 to 8 am in the form of fasting. Serum vaspin concentration and lipid profiles were determined by ELISA method using a special kit for Human vaspin of EASTBIOPHARM Co., Pars Azmun kit and according to the manufacturer's instructions.

\subsection{Statistical methods}

To recognize similarity and normality of the data related to the subjects of the research groups was used Shapiro-Wilk test. To analyze the data was used the paired T test and the covariance test to show differences within group and between groups at the level of 5\%. Statistical calculations were done by SPSS 21.

\section{Results}

As shown in Table 1, the subjects before the implementation of study protocol, in terms of which age, weight and body composition were homogenous, had no significant different with each other. data analysis showed that 8-week exercise had a significant effect on BMl $(P=0.001)$, weight $(P=0.000)$, vaspin $(P=0.003), H D L(P=0.000), L D L(P=0.001)$, and TC $(P=0.001)$, while had no significant effect on TG $(P=0.692)$.

Table 1. The average variables for the control and experimental groups in the pre and post-test

\begin{tabular}{|l|c|c|c|}
\hline Variable & phase & control group & experimental group \\
\hline Height $(\mathrm{cm})$ & Pre-test & a5.1 \pm 161.1 & $160.2 \pm 6.6 \#$ \\
\hline Age (year) & Pre-test & $6.2 \pm 39.7$ & $37.1 \pm 7.3$ \\
\hline Weight $(\mathrm{kg})$ & Pre-test & $9.2 \pm 75.6$ & $80.7 \pm 9.7$ \\
\hline
\end{tabular}




\begin{tabular}{|c|c|c|c|}
\hline & Post-test & $8.9 \pm 75.6$ & $78.8 \pm 9.7 \#^{*}$ \\
\hline \multirow[t]{2}{*}{ BMI (2kg / m) } & Pre-test & $2.4 \pm 29.1$ & $31.4 \pm 2.8$ \\
\hline & Post-test & $2.3 \pm 29.1$ & $30.7 \pm 2.9 \#^{*}$ \\
\hline \multirow[t]{2}{*}{$\mathrm{TC}(\mathrm{mg} / \mathrm{dl})$} & Pre-test & $56.4 \pm 199.1$ & $204.5 \pm 35 / 0$ \\
\hline & Post-test & $57.9 \pm 200.6$ & $198.7 \pm 0.2 \#^{*}$ \\
\hline \multirow[t]{2}{*}{ TG (mg / dl) } & Pre-test & $30.4 \pm 135.6$ & $118.9 \pm 27.4$ \\
\hline & Post-test & $32.2 \pm 141.3$ & $121.2 \pm 36.4$ \\
\hline \multirow[t]{2}{*}{$\mathrm{HDL}(\mathrm{mg} / \mathrm{dl})$} & Pre-test & $7.6 \pm 43.6$ & $40.4 \pm 6.5$ \\
\hline & Post-test & $8.1 \pm 41.2$ & $42.9 \pm 6.4 \#^{*}$ \\
\hline \multirow[t]{2}{*}{ LDL (mg / dl) } & Pre-test & $23.2 \pm 123.4$ & $120.1 \pm 22.0$ \\
\hline & Post-test & $23.2 \pm 124.1$ & $106.2 \pm 15.9 \#^{*}$ \\
\hline \multirow[t]{2}{*}{ Vaspin (mg / dl) } & Pre-test & $2.09 \pm 4.99$ & $4.42 \pm 3.16$ \\
\hline & Post-test & $2.07 \pm 5.29$ & $2.78 \pm 2.21 \#^{*}$ \\
\hline \multicolumn{4}{|c|}{ a Data are shown as mean \pm standard deviation. } \\
\hline \multicolumn{4}{|c|}{ \# T test for dependent samples is significant (significant difference in the experimental group before and after 8 sessions) $(p<0.05)$. } \\
\hline
\end{tabular}

\section{Discussion and Conclusion}

One of the important results of the present study was a significant reduction in serum vaspin after rhythmic aerobic exercise. This study is among the randomized and controlled trials on the effect of the first rhythmic aerobic exercise on serum vaspin levels in overweight and obese women. Vaspin significant reduction in this study is in line with the findings of Nezam-Dust () and Daryanush (), and is not consistent with the findings of Hosseini (), Shafi'i () and Sadeghipur (). The cause of difference in the results can be due to difference in the type of the subjects, the intensity and duration of exercise program. Explaining this paradox is very difficult, since the exact mechanism of vaspin function has not fully been understood $(26,27)$. Sadeghipur et al. examined the twelve weeks alternative aerobic exercise on the boy students having overweight (). The cause of difference in the results as compared to the present study is likely due to difference in the ways of aerobic exercise as well as the genus and age of the subjects. Hosseini et al. reported that the eight week aerobic exercise with 55 to 65 per cent of maximum heart rate per person is led to a significant increase in vaspin (). Probably the intensity difference of the training and the average $\mathrm{MBI}$ of the subjects has caused difference in the results. Some researchers such as Cho et al. (2010) and Youn et al (2008) reported that serum vaspin concentration is lower in people with high levels of physical fitness compared to those with low physical fitness (). In addition, the results of Lee et al. (2010) showed that serum vaspin concentrations reduce in obese children after seven days lifestyle modification (). Kloting et al. (2012) stated that insulin sensitivity is, in fact, the important and strong determinant of vaspin gene expression in adipose tissue, and the high levels of vaspin in obese people is, in fact, a compensatory mechanism in response to decreasing insulin sensitivity and reducing glucose metabolism. The researchers have attributed decreasingv levels to increasing insulin sensitivity resulting from the exercise. Of course, Eberbach et al. (2010) found that serum vaspin level decreases after the four weeks training. They stated that vaspin changes is independent of insulin sensitivity and its changes introduced depending on the conditions of oxidative stress resulting from exercise training (). Handisurya et al. (2010) in their study, which examined the concentration of vaspin in relation to insulin sensitivity after weight loss resulting from laparoscopy, showed that weight loss after surgery in 33 subjects with excessive obesity leads to decrease vaspin levels, insulin, BMI, and insulin resistance. Furthermore, the changes of serum vaspin concentration are positively correlated with the changes of insulin resistance levels (). The results of the present study showed that rhythmic aerobic exercises have been effective in the weight loss and body composition of training group. Hence, it seems that weight loss is one of the main mechanisms of reducing serum vaspin after rhythmic aerobic exercises. In the present study, after the eight weeks rhythmic aerobic exercise, decreased the levels of BMI, LDL and TC of the experimental group, their HDL showed a significant increase. In other words, the lipid profile of the control group worsened and vice versa, the lipid profile of the experimental group improved.

Regardless of the type of subjects, in terms of the positive impact of aerobic exercise on lipid profile, the results of the present study are consistent with previous studies on lipid profile (), including in one of these that was conducted for ultra-analytic study by Kelly et al (2004) on 1955 women 18 years and older, TC, LDL and TG reduced 2, 3 and 5 per cent, respectively and HDL increased 3 per cent (). In addition, in another ultra-analytic study was conducted by the same researcher (2005) on 1427 aged subjects (the age-range of 55 to 77.9-year-old), TC, LDL and TG decreased 1.1, 5.6 and 5.9 per cent, respectively and $\mathrm{HDL}$ increased 6.5 per cent. BMI also decreased 1.1 per cent (), in this respect which is consistent with the present research. Reducing harmful lipids can be associated with physical activity with 
cardiorespiratory fitness and the relationship of both to body fat mass and blood lipids (). Moreover, this improvement can be attributed reducing inflammation caused by aerobic exercise with moderate intensity (). Aerobic exercises can be as an effective method for the changes in lipid profile. It seems that physical activities increase lipolysis and also decrease fatty acids in the blood and muscles. This, in turn, excess layer of fat (free cholesterol and phospholipid) creates which is transferred to $\mathrm{HDL}$ and increases it (28). Another possible reason for the increase in $\mathrm{HDL}$ is increasing its production by the liver after changing the activity of enzyme LPL and decreasing hepatic lipase after physical activity (29). The reduction of LDL depends on body weight and fat loss. Changing in body composition, increasing muscle mass and reducing fat mass can be an important factor in decreasing LDL. In addition, physical activity makes active Lecthincholestrol Acyltransferase (LCAT) and enables the feeding of HDL particles (1). Also shown during exercise and thenceforth, reducing plasma insulin and possibly reducing insulin causes to make active lipolysis of adipose tissue and increase the concentration of plasma free fatty acid. Along with the decrease in insulin, glucagon secretion increases, this accelerates the process of lipolysis $(30,31)$. Studies have shown that in people with hypothyroidism by reason of lower LDL cholesterol receptors on the surface of liver cells, cholesterol metabolism decreases (32), leading to an increase in levels of serum cholesterol and LDL cholesterol and lower HDL cholesterol level (4). This can be the reason for the increase in LDL in the control group. In the present study, the reduction of vaspin levels were observed along with reducing levels of $B M I, L D L$ and $T C$, to some extent indicates anti-inflammatory effects and usefulness of this type of training. It seems that lower serum vaspin levels in the experimental group compared to the control group is an adjustment mechanism due to a significant decrease in BMI. Probably reducing vaspin has been affected by reducing the level of inflammatory parameters. Improving the levels of lipid profile may also represent an effective role of the training on reducing BMI and lipolysis. In general, it seems that likely reducing inflammation caused by weight loss and body composition among the subjects of this study has led to the reduction of vaspin in serum levels of these people. Moreover, reducing body composition had a positive effect on decreasing harmful blood lipids, including LDL, TC and $\mathrm{HDL}$. But, since the exact mechanism of vaspin performance is not clear and the present study is of the first studies on the effect of rhythmic aerobic activity on vaspin and lipid profile, therefore, it needs to deeply examine the effective mechanisms on changing this adipokine related to inflammation after the rhythmic aerobic exercise.

\section{Acknowledgments}

The authors would like to thank the women participating in the project for their useful co-operation.

\section{References}

Antunes TT, Gagnon A, Chen B, Pacini F, Smith TJ, Sorisky A.(2006) Interleukin-6 release from human abdominal adipose cells is regulated by thyroid-stimulating hormone: effect of adipocyte differentiation and anatomic depot.Am J Physiol Endocrinol Metab; 290(6): E11404.

Azizi F, Salehi P, Etemadi A, Zahedi-Asl S.(2003),Prevalence of metabolic syndrome in an urban population: Tehran lipid and glucose Study. Diabetes Res Clin Pract , 61:29-37.

Braith RW, Beck DT.(2008),Resistance exercise: training adaptations and developing a safe exercise prescription. Heart Fail Rev .13:6979.

Braith RW, Kerry JS.(2006 ) Resistance exercise training : Its role in the prevention of cardiovascular disease. Circulation , 113 :2642 2650.

Bray ,G,A, Bouchard ,C, James ,W,P,T, eds.(1998). Handbook of obesty. New York: Marcel Dakker, 11.

Cauza E, Hanusch-Enserer U, Strasser B, Ludvik B, Metz-Schimmerl S, Pacini G, Wagner O, Georg P, Prager R, Kostner K, Dunky A, Haber $P$. The relative benefits of endurance and strength training on the metabolic factors and muscle function of people with type 2 diabetes mellitus. Arch Phys Med Rehabil 2005; 86(8): 1527-33.

Central vaspin administration acuteiy reduces food intake and has sustained blood glucose- lowering effects. Diabetologia , 54(7): 181923.

Chang HM, Lee HJ, Park HS, Kang JH, Kim KS, Song YS, et al.(2010) Effects of Weight Reduction on Serum Vaspin Concentrations in Obese Subjects: Modification by Insulin Resistance. Obesity 18: 2105-10.

Cho JK, Han TK, Kang HS.(2010) Combined effects of body mass index and cardio/respiratory fitness on serum vaspin concentrations in Korean young men. Eur J Appl Physiol; 108: 347-353.

Green JS, Low RC, Pronk N, Jacobsen D, Rohack JJ, Crouse S, and et al. (2005)Low and high intensity endurance exercise training does not significantly alter the apolipoprotein -b/ apolipoprotienal ratio in hypercholesterolemic men. Med Sci Sport Exer, 37:470 -478 .

Gutin B1, Barbeau P, Owens S, Lemmon CR, Bauman M, Allison J, Kang HS,(2002) Litaker MS. Effects of exercise intensity on cardiovascular fitness, total body composition, and visceral adiposity of obese adolescents. Am J Clin Nutr; 75(5): 818-26. 
Handisurya A, Riedl M, Vila G, Maier C, Clodi M, Prikoszovich T, et al.(2010) Serum vaspin concentrations in relation to insulin sensitivity following RYGB- induced weight loss. Obes Surg 20 (2): 198- 203.

Hida K, Wada J, Eguchi J, Zhang H, Baba M, Seida A, et al. (2005)Visceral adipose tissue-derived serine protease inhibitor: a unique insulin-sensitizing adipocytokine in obesity. Proc Natl Acad Sci USA ,102: 10610-5.

Hida K, Wada J, Zhang H, Hiragushi K, Tsuchiyama Y, Shikata K, et al. (2000). Identification of genes specifically expressed in the accumulated visceral adipose tissue of OLETF rats. J Lipid Res , 41: 1615-22. 2000.

Jung CH, Lee WJ, Hwang JY, Seol SM, Kim YM, Lee YL, et al.(2011) Vaspin protects vascular endothelial cells against free fatty acidinduced apoptosis through a phosphatidylinositol 3- kinase/Akt pathway. BBRC , 413: 264-9.

Kadoglou NP, Fotiadis G, Kapelouzou A,Kostakis A, Liapis CD, Vrabas IS. The differential anti-inflammatory effects of exercise modalities and their association with early carotid atherosclerosis progression in patients with type 2 diabetes. Diabet Med, 30(2): 41-50. 2013.

Karlsson EA, Beck M. (2010). The burden of obesity on infectious disease. Exp Biol Med (Maywood). 235(12):1412-24.

Kawano K, Hirashima T, Mori S, Saitoh Y, Kurosum M, Natori T. (1992) Spontaneous long-term hyperglycemic rat with diabetic complications, Otsuka Long-Evans Tokushima Fatty (OLETF) strain. Diabetes ,41:1422-8. 1992.

Kershaw EE, Flier JF.(2007) Adipose tissue as an endocrine organ. J Clin Endocrinol Metab 2004; 89: 2548-56. 2.MacDougald OA, Burant CF. The rapidly expanding family of adipokines. Cell Metabolism ,6: 159-61.

Kloting N, Kovacs P, Kern M, Heiker JT,Fasshauer M, Schön MR, et al. (2012

Kyle UG, Shutz Y, Pichard C. (2003) Body composition interpretation . Contributions of the fat -free mass index and body fat mass index. J Nutrition $19: 123-131$.

Lambers S, Van Laethem C, Van Acker K, Calders P. (2008) Influence of combined exercise training on indices of obesity, diabetes and cardiovascular risk in type 2 diabetes patients. Clin Rehabil; 22(6): 483-92.

Lee MK, Jekal Y, Im JA, Kim E, Lee SH, Park JH, et al. (2010) Reduced serum vaspin concentrations in obese children following shortterm intensive lifestyle modification. Clin Chim Acta , 411: 381-5.

Mack MG, Shaddox LA.(2004) Changes in shortterm attitudes toward physical activityand exercise of university personal wellness students. College Student Journal; 38(4): 587-93.

Oberbach A, Kirsch K, Lehmann S, Schlichting N,Fasshauer M, Zarse K, et al.(2010) Serum vaspin concentrations are decreased after exercise-induced oxidative stress. Obes Facts , 3(5): 328-331.

Olefsky ,J,M : Obesty in harrisons princiles of internal medicine isselbacher at al,(1994) chapter 73. McGraw-Hill, Inc. New York.

Parente B, Guazzelli I, Ribeiro MM, Silva AG. (2006) Obese children lipid profile:Effects of hypocaloric diet and aerobic physical exercise. J Endocrino Metaboli ,50:499 -504.

Patrick D, Savage M, Brochu M. (2003) Reduction in obesity and coronary risk factors after high caloric training in overweight coronary. America Heart Journal ,146:317-323.

Rahimi, N., Marandi, S.M., and Karegar-Fard, M. (2011). The effect of 8 weeks training in the water on lipid profile in patients with type II diabetes. 29 (148): 988-996.

Roque FR, Hernanz R, Salaices M, Briones AM.(2013) Exercise training andcardiometabolic diseases: focus on the vascular system. Current Hypertension Reports, 15(3): 204-14.

Safarzadeh, A.R., Gorgani, E. (2012). The effect of progressive resistance training on serum vaspin levels and some inflammatory parameters in male rats. Kumesh, Volume 14, Issue 1 (45).

Seeger J, Ziegelmeier M, Bachmann A, Lossner U, Kratzsch J, Blu HM, et al.(2010) Serum levels of the adipokine vaspin in relation to metabolic and renal parameters. J Clin Endocrinol Metab,93 (1):247- 251.

van Loon LJ.(1985) Use of intramuscular triacylglycerol as a substrate source during exercise in humans. J Appl Physiol 2004; 97(4): $1170-87$.

Wallace MB, Mills BD, Browning CL.(1997) Effects of cross-training on markers of insulin resistance/hyperinsulinemia. Med Sci Sports Exerc ,29:1170-1175.

WHO consultion on obesity.(1997) Preventing and manging the global epidemic. Geneva: World Health Organization, 1-276.

Youn BS, Klöting N, Kratzsch J, Lee N, Park JW, Song ES, et al. (2008)Serum vaspin concentrations in human obesity and type 2 diabetes. Diabetes; 57: 372-377. 